\title{
Determinants of Ethiopian Commodity Exchange Participants Membership Category
}

\author{
Gebrekiros G/Medhin Berhe \\ Federal Technical and Vocational Education and training institute, Addis Ababa, Ethiopia
}

\begin{abstract}
Purpose: The Ethiopian Commodity Exchange (ECX) was established to revolutionize Ethiopian agriculture and transform the economy through introducing a dynamic, efficient and transparent marketing system. Properly implemented and regulated, commodity exchanges can contribute greatly to the achievement of a country's economic and developmental goals and strengthen the bargaining power of participants. Hence the overall objective of this study is to assess the trading practices and challenges of the newly established commodity exchange in Ethiopian.

Design/Methodology/Approach: The study adopted a descriptive cross-sectional research design. Using a structured questionnaire survey by interviewing a sample of 80 randomly selected participants an analyzed using both descriptive and inferential data analysis techniques.

Findings: The study found that practicing an open outcry and spot contract trading system. Results of the econometric-model analysis revealed that time of participation, limited membership seat, membership seat fee and occupation were found to be significant predictors that influence the choice of membership category. Result of the study also indicated that lack of adequate warehouses, grading and sampling system, higher penalty cost related to warehouse service, availability of in-store credit, higher membership seat fee and transaction cost, were found to be some of constraints that hinder participants from the smooth functioning of transactions in the exchange.

Originality/value: This study is important especially to policymakers and development practitioners to make informed decisions in an effort to transform the economy through strengthening transparent marketing system in the country. In this regard, this study provides valuable information and evidence on the performance and challenges of ECX.
\end{abstract}

Keywords: ECX, ECX participants, trading practice, quality grading system, market information system DOI: $10.7176 / \mathrm{EJBM} / 12-25-01$

Publication date:September $30^{\text {th }} 2020$

\section{INTRODUCTION}

In the era of globalization, how the commodity market exchange is organized and coordinated is increasingly became a fundamental concern of all nations across the world. More specifically, linking buyers and sellers into the commodity market for the effective and efficient transactions among the participants is the most challenging task in most developing countries, as they lack the basic infrastructure for the exchange. In response to this and following market liberalization and increasingly affordable information technology since 1990, commodity exchanges have mushroomed around the world.

Commodity derivatives exchanges provide a platform where traders and investors from various parts of the world can participate in the hedging and price discovery of any listed commodity (Bose, 2009). Instruments (contracts) traded on commodity exchanges include futures, options and other derivatives. Trading in these instruments began with floor trading, also called open outcry systems. In open outcry systems, traders assembled in a pit in the exchange and traded commodities by indicating their bids or offers to others in the pits. Commodity futures markets help with price discovery and provide a way to hedge for producers and buyers of commodities (Thomas, 2008).

The Ethiopian Commodity Exchange was established in 2008 to revolutionize Ethiopian agriculture and transform the economy through a dynamic, efficient and transparent marketing system that serves all and essentially turns a commodity into assets. And properly implemented and regulated, commodity exchanges can contribute greatly to the achievement of a country's economic and developmental goals and strengthen the bargaining power of weak groups such as small farmers.

Since its establishment, there were no adequate studies that identified the trading practices and challenges of the participants of the commodity exchange. As findings of Tollens, (2006) revealed that market information and commodity exchanges can be powerful instruments to inform participants about market conditions and prices, to find willing buyers, to empower them by making the transactions more equal and fair, to inform them about the optimal timing of buying and selling, to induce them to store optimally and to plan ahead, making better informed optimal production and marketing decisions. This thus helps to break the vicious poverty trap, inducing resilience and better coping mechanisms, and reducing inequality in the markets.

The Ethiopian commodity exchange is young established with bright vision and mission to the economic development of the country in general and to the individual participants at the grass-root level. In a country like 
Ethiopia where a predominantly agrarian society dominates, agriculture is the backbone of the country's development endeavor. Despite this agricultural product marketing were not given much attention and were not getting its real value for the last consecutive decades.

Eleni and Ian Goggin (2005) indicated that producers of agricultural products and the country at large were facing different challenges due to ineffective use of commodity exchange. Researches regarding the Ethiopian commodity exchange participants ${ }^{1}$ are very limited and the challenges they face are not articulated and described yet.

This research is, therefore, an attempt to assess the trading practice and identify the constraints of the participants that arise from market information, storage (warehouse), quality grade (standard), regulation, and liquidity, of the Ethiopian commodity exchange.

\section{Objectives of the Study}

The overall objective of the study is to assess the trading practices and identify the challenges of participants of the Ethiopian commodity exchange. Specific objectives include

- To assess the trading practices of the Ethiopian Commodity Exchange

- To assess the regulation system of the exchange

- To identify the challenges of Ethiopian Commodity Exchange participants

\section{Overview of the Ethiopian Commodity Exchange}

The Ethiopian Commodity Exchange (ECX) is designed to be a marketplace where buyers and sellers meet to trade, assured of quality, delivery and payment. It will manage a system of daily clearing and settling of contracts. It will enhance market efficiency by operating a trading system where buyers and sellers use standardized contracts. Market transparency will be achieved by disseminating market information in real-time to all market players (ECX, 2008).

Trading in ECX takes place on a physical trading floor located in Addis Ababa, where buyers and sellers participate in "open outcry" bidding (Jennie, 2010). The ECX uses several ways to transmit these prices in realtime to producers and consumers directly. Once a deal is made, the ECX credits the seller's account and transfers title of the commodity to the buyer. The buyer then needs to collect its goods within 10 days from the warehouse where the product was deposited.

Once the product is deposited in the ECX warehouse, the ECX samples, grades, weighs and certifies the product according to ECX established and Products are stored in the ECX warehouse, and an Electronic Warehouse Receipt is issued to the depositor or his/her representative (ibid).

ECX is supposed to guarantee: market integrity: guaranteeing the product grade and quantity and operating a system of daily clearing and settling of contracts; efficient coordination of buyers-sellers and standardized contracts; market transparency: disseminating market information in real-time to all market players; and managed risks (Seifu, 2010). Currently, the exchange is focusing on spot and open outcry trading system.

ECX Members are the core actors of the market. Membership is acquired through the purchase of a Membership Seat, provided other requirements are met. A Membership Seat is a permanent and transferable right to trade on the Exchange. Members are required to follow the Rules of the Exchange and thus maintain the integrity of the ECX marketplace (Alemu et al., 2010).

\section{RESEARCH METHODOLOGY}

The study employed both quantitative and qualitative research tool in order to produce a richer and more factual report. To this end, cross-sectional survey method was employed.

\section{Source of Data}

The source of data for this study comprises of both primary and secondary sources. Primary data source was collected through employing questionnaire and key informant interviews in order to assess trading practices and to identify the main challenges of the Ethiopian commodity exchange participants. To support the collected primary data sources direct observation was also conducted. In addition to this, Secondary source of data was also used for the study inter alias include data from ECX, published and unpublished materials and electronic sources.

\section{Sample Size and Sampling procedure}

The study employed standard statistical formula to determine the sample size of the study ( 80 member participants) out of the total study population (498 ECX participants, which were categorized as full members and limited members of ECX), engaged in buying, selling and exporting of commodities in Addis Ababa city. The sample was

\footnotetext{
${ }^{1}$ Participants (exchange actors): any person recognized as a member participant by the authority who engages in the business of buying and selling in the exchange trade contracts for others or for his/her Owen account in the ECX.
} 
selected through a two-stage stratified random sampling technique using proportional to size allocation, which in this case was the major unit of analysis. The sampling frame, list of the commodity exchange participants or actors, was taken from ECX. The Ethiopian commodity exchange participants included in the sample were those commodity actors who are the legal members of the Ethiopian commodity exchange those, who start the exchange from its establishment. Furthermore, key informant interview was held with knowledgeable informants, who among others include warehouses operation officers, membership relation officers, quality grading officers and member participants.

Since the sampling frame consists of heterogeneous membership type categories, the appropriate sampling technique for the research was found to be a stratified sampling technique. The sample size of each stratum was decided based on proportional sampling method. Selections of key informants were carried out in consultation with concerned bodies of the Ethiopian commodity exchange coordination office.

\section{Data Collection Instruments}

Appropriate questionnaires were prepared and used for the survey. Respondents were told what the research was all about in the language that they can understand. Respondents in this study were speakers of Amharic. Therefore, the questionnaire was translated into the language that they can understand. Doing so was very important for respondents to easily understand the questionnaire and express their ideas comfortably. A pilot test of the questionnaire was carried out at Humera commodity exchange. Feedback obtained from the pilot test was used to refine the questionnaire. Out of the total 80 questionnaires administered, 73 were found filled appropriately and considered for analysis.

\section{Data Analysis}

Both descriptive and inferential data analysis techniques were employed to analyze the data. A descriptive method of data analysis was employed using Statistical Package for Social Studies (SPSS) to describe the major variables under consideration. Besides binary logistic regression was used to sort out the relative strength of explanatory variables which are expected to influence the decision and status of participants' membership category.

\section{Binary Logistic Regression Model specification}

Binary regression model is amongst the most popular categories of econometric techniques employed to identify determinants of a given dummy dependent variable, which in this case is status of membership participation category. In so many cases, logistic regression is preferred to the others due to its link to other models and allows bringing out patterns in the data that might be obscured. Thus, this study employed Binary Logistic Regression model so as to investigate determinants of status of membership participation category. Specification of the model is depicted below. Norusis (1994) pointed out that in logistic regression model, an attempt will be made to directly estimate the probability of an event occurring. For the case of a single independent variable, the model can be written as:

Prob (event) $=\frac{\mathrm{e}^{\mathrm{Bo}+\mathrm{B} 1 \mathrm{X}}}{1+\mathrm{e}^{\mathrm{Bo}+\mathrm{B} 1 \mathrm{X}}}$

Or equivalently, Prob (event) $=\frac{1}{1+\mathrm{e}^{-(\mathrm{Bo}+\mathrm{B} 1 \mathrm{X})}}$

Where $\mathrm{B}_{\circ}$ and $\mathrm{B}_{1}$ are coefficients to be estimated from data

$\mathrm{X}$ is the independent variable

e is the base of the natural logarithms, approximately 2.718 .

For more than one independent variable the model can be written as

$$
\begin{array}{cc}
\text { Prob (event) }= & \frac{\mathrm{e}^{\mathrm{Z}}}{1+\mathrm{e}^{\mathrm{Z}}} \\
\begin{array}{c}
\text { Or equivalently, } \\
\text { Prob (event) }=
\end{array} & \frac{1}{1+\mathrm{e}^{-\mathrm{Z}}}
\end{array}
$$

Where, $\mathrm{Z}$ is the linear combination of independent variables written as

$$
\mathrm{Z}=\mathrm{B}_{\mathrm{o}}+\mathrm{B}_{1} \mathrm{X}_{1}+\mathrm{B}_{2} \mathrm{X}_{2}+\ldots+\mathrm{B}_{\mathrm{p}} \mathrm{X}_{\mathrm{p}}
$$

The probability of an event not occurring is estimated as Prob (no event) $=1$ - Prob (event)

Rearrangement of the equation facilitates the understanding and interpretation of the coefficients of the logistic regression model. The model can be re-written in terms of the log odds of an event occurring, which is called logit. The odds of an event occurring are defined as the ratio of the probability that it will occur to the probability that it will not (ibid).

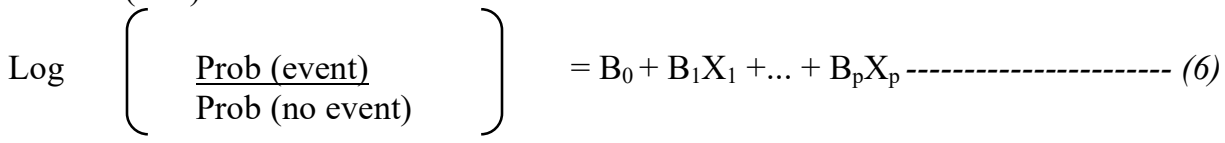


From equation 6 , the logistic coefficients can be interpreted as the change in the log odds associated with a unit change in the independent variable. Since it is easier to think of odds rather than log odds, the above equation can be re-written in terms of odds as:

$\underline{\operatorname{Prob}(\mathrm{event})}=e^{B o+B I X 1+\ldots+B p X p}=e^{B o} e^{B 1 X 1 \ldots} e^{B p X P}$

Prob (no event)

Then e raised to the power $B_{i}$ is the factor by which the odds change when the $i^{\text {th }}$ independent variable increases by one unit. If $B_{i}$ is positive, the factor will be greater than 1, which means that the odds are increased. If $B_{i}$ is negative, the factor will be less than 1 , which means that the odds are decreased. When $B_{i}$ is zero, the factor equals 1 , which leaves the odds unchanged.

\section{Results and Discussion}

\section{Brief Description of the Study Population}

As depicted below in table 1 , about $85 \%$ of the respondents were male and only $15 \%$ were females. This shows that the major participants in the Ethiopian commodity exchange were dominantly male business owners. With regard to the age category of the respondents, $56.2 \%$ of the respondent's age was found to be within the range of 31-65 years, while the rest of the participants (42.5\%) were found to be youngsters. the majority (67.1\% \%) of the respondents' were found attaining tertiary level educational background.

Regarding the occupation of participants, the majority of the respondents $(75.3 \%)$ were found to be full-time merchants. In line with this, results of the key informant interviewee indicated that, full-time merchants are relatively committed and give their time and resource to the business activities than those par timers. The rest of the respondents $13.7 \%$ and $11 \%$ were government employees and students respectively.

Table 1: Socio-Demographic Characteristics of ECX Participants

\begin{tabular}{|c|c|c|c|c|}
\hline & & Frequency & Percent & t-test \\
\hline \multirow{3}{*}{$\operatorname{sex}$} & Male & 62 & 84.9 & \multirow[t]{3}{*}{ Sig. } \\
\hline & Female & 11 & 15.1 & \\
\hline & Total & 73 & 100.0 & \\
\hline \multirow[t]{4}{*}{ Age } & $15-30$ year & 31 & 42.5 & \\
\hline & $31-65$ year & 41 & 56.2 & \\
\hline & $>65$ year & 1 & 1.4 & \\
\hline & Total & 73 & 100.0 & \\
\hline \multirow[t]{4}{*}{ Educational status } & Primary level & 6 & 8.2 & \multirow{4}{*}{.667} \\
\hline & Secondary level & 18 & 24.7 & \\
\hline & Tertiary & 49 & 67.1 & \\
\hline & Total & 73 & 100.0 & \\
\hline \multirow[t]{4}{*}{ Occupation } & Merchant & 55 & 75.3 & \multirow[t]{4}{*}{.364} \\
\hline & Student & 8 & 11 & \\
\hline & Government employee & 10 & 13.7 & \\
\hline & Total & 73 & 100.0 & \\
\hline
\end{tabular}

Trend and Membership categories of ECX Participants

As results of the study depicted in the figure below indicate, about a fourth $(24.7 \%)$ of the respondents reported that they started participating in the Ethiopian commodity exchange since its establishment in 2008 . Whereas, $23.3 \%$ of the respondents registered as a participant of the commodity exchange after 1 year of its establishment (2009). The remaining $38.4 \%$ and $13.7 \%$ of the respondents reported as they started to participate as of 2011 and 2010 respectively. The trend of ECX membership participation was found to be unpredictable, more specifically in 2009 and 2010 the figure indicated a downward trend. In line with this, results of the key informant interviewee indicated that the trend is highly associated with the misconception related to lack of awareness and limited promotion of ECX and well-organized system that can attract the participant to the exchange system. 


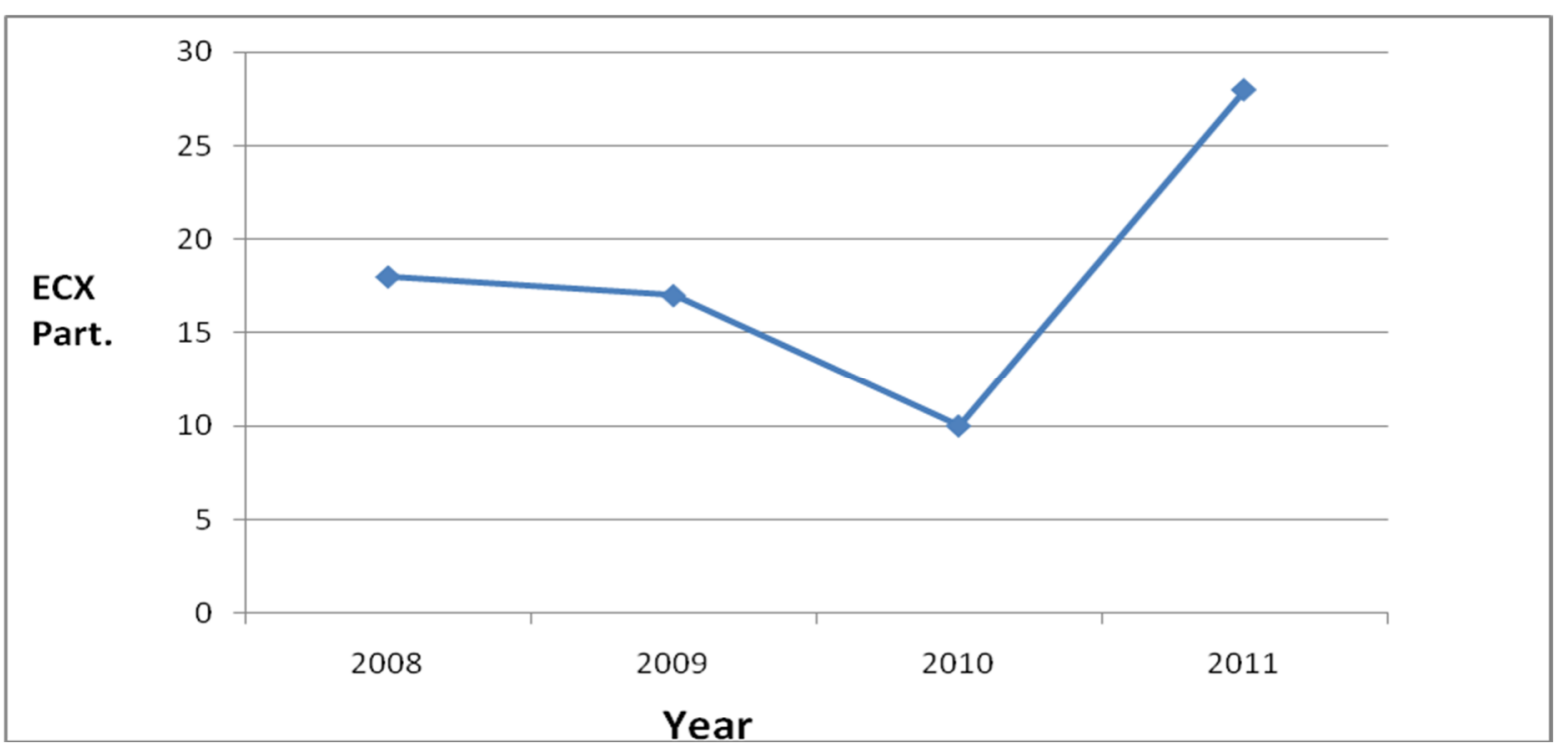

Source: Own source, 2011

Figure 1- Trend of ECX membership

Table 2: The Distribution of Membership Categories of ECX Participants

\begin{tabular}{llll}
\hline & & Frequency & Percent \\
\hline Membership category & Full trading member & 9 & 12.3 \\
& Full intermediary member & 27 & 37 \\
& Limited trading member & 12 & 16.4 \\
& Limited intermediary member & 25 & 34.3 \\
& Total & 73 & 100.0 \\
Best membership category & Full trading member & 30 & 41.1 \\
& Full intermediary member & 41 & 56.2 \\
& Limited intermediary member & 2 & 2.7 \\
& Total & 73 & 100.0 \\
\hline
\end{tabular}

Source: Own source, 2011

With regard to membership category, a relatively higher percent of the respondents $37 \%$ and $34.3 \%$ replied as they are full intermediary members and limited intermediary members respectively. While $16.4 \%$ and $12.3 \%$ were found to be limited trading members and full trading members of the exchange.

A perusal of the analysis with regard to best membership category, a considerable proportion of the respondents $(56.2 \%)$ indicated that full intermediary membership as the best compared with other ECX membership categories. The opportunity associated with the Full intermediary membership category including buying and selling all types of commodities for their own account and for others was among the major reason for the participant to designate it as best membership category. On the other hand, about $41.1 \%$ of the respondents' replied that their best membership category is full trading membership as this membership gives them the advantage to buy and sell all types of commodities for themselves. From the aforementioned result and analysis, it was found out that majority of the limited membership participant $(92.4 \%)$ were found participating in a membership which they were not interested to participate. This according to the key informant interviewee leads to lower level of participant's engagement and performance in the Ethiopian commodity exchange.

\section{Practice and Challenges of the Ethiopian Commodity Exchange Trading Practice}

As results of the on spot observation and document analysis revealed, the ECX was applying open outcry trading system. Although electronic trading is Practically preferred and employed all over the world as a means of facilitating the exchange system, the system is not yet considered in ECX as a means to facilitate the exchange due to poor ICT infrastructure and awareness problem of the ECX participants. Consistent with this, key informants mentioned that price movement, ICT related problems and lower seeped of transactions were found to be the major problems associated with the open outcry trading system. Consistent with this, findings of Thomas (2008) revealed that electronic trading leads to reduced price movement, lower volatility, lower risk in the market and higher 
liquidity by increasing the speed of transactions and lowering transaction costs. But according to the information obtained from ECX participant the existing exchange system is operating well, although much have been left to be done to make it more functional.

Although ample literature confirmed the immense role of commodity exchange in reducing transaction cost, the results of this study revealed the otherwise. According to the findings of this study, about $68.5 \%$ of the respondents replied as participating in the Ethiopian commodity exchange increased the transaction costs than the traditional trading system. Costs for warehousing, quality grading, warehouse related services, ECX, intermediary among others were mentioned as the probable reason for high transaction cost. Unlike the aforementioned result, $30.1 \%$ of the respondents who participate in ECX were replied as participating in ECX reduced their transaction cost while an insignificant number of respondents (1.4\%) replied as transaction cost in ECX and the traditional trading system were the same. In contrary to the findings of this study, Gebremedhin et al., (2005) found that commodity exchange plays a pivotal role in reducing transaction costs by offering services at lower cost than that which participants in the commodity sectors would incur if they were acting outside an institutional framework.

With regard to the contractual agreement, on spot observation and document analysis results of the study revealed that Ethiopian commodity exchange has was practically employing spot contract agreement system. As results of key informant interviewee revealed this trading agreement system was not such encouraging and promising due to problems associated with price fluctuation. As results of the finding portrayed below in table 3 verify, about $56.2 \%$ of the respondents replied that the ECX membership seat fee is expensive and unfair while $42.4 \%$ revealed the membership seat fee is fair and easy to afford. In line with this key informants mentioned that the membership seat fee was decided by the member's bid agreement, not by the ECX.

Table 3: Trading practice

\begin{tabular}{llll}
\hline Characteristics & Response & No of respondents & Percent \\
\hline Membership seat fee & Expensive & 41 & 56.2 \\
& Cheap & 1 & 1.4 \\
& Fair & 31 & 42.4 \\
& Total & 72 & 100.0 \\
membership requirement & Encouraging & 47 & 64.4 \\
& Discouraging & 26 & 35.6 \\
& Total & 73 & 100.0 \\
Transaction costs & reduced transaction cost & 22 & 30.1 \\
& increased transaction cost & 50 & 68.5 \\
& no difference & 1 & 1.4 \\
\hline
\end{tabular}

\section{Market Information System}

Asked about their level of satisfaction related ICT service availability, about $41 \%$ of the respondents confirmed that the available information communication technology of the Ethiopian commodity exchange facilities was satisfactory. In contrary to this a relatively higher percent of the respondents $(59 \%)$ reported their dissatisfaction regarding the ICT system and service provided by as shown in the table below. Consistent with this, key informants $i$ also confirmed the limited and unsatisfactory service of ECX with regard to the use of ICT to facilitate the transaction. . In line with this, findings of the study by Eric (2006) revealed that with full application and development of ICT, the commodity exchange market information system will have lower transaction costs and improve market efficiency, and thereby enhance smallholder farmer access to markets and lower market risks. Despite the limited ICT infrastructure, the vast majority of the respondents reported that they are getting timely market-related information from the ECX. According to these respondents, the Ethiopian commodity exchange manages to provide market related information related to market prices, commodity volumes and market conditions and also price trend data through the use of different market information communication systems as shown in the table below. 
Table 4: Market information System dissemination of ECX

\begin{tabular}{llll}
\hline \multirow{2}{*}{ ICT facility of ECX } & Response & No of respondents & Percent \\
\cline { 2 - 4 } & satisfactory & 30 & 41 \\
& No & 43 & 59 \\
& Total & 73 & 100.0 \\
\hline Use of Newspaper and Magazine sources & Yes & 17 & 23.3 \\
& No & 56 & 76.7 \\
\hline Use of Mass media & Total & 73 & 100.0 \\
\hline SMS users & Yes & 26 & 35.6 \\
& No & 47 & 64.4 \\
& Total & 73 & 100.0 \\
\hline Internet database system users & Yes & 43 & 58.9 \\
& No & 30 & 41.1 \\
\hline ICT network condition for & Total & 73 & 100.0 \\
internet and SMS user & Yes & 38 & 52.8 \\
\hline Actual price at the time of sale or buy usually the same & Yes & 34 & 47.2 \\
as compared to the local market & No & 72 & 100.0 \\
\hline
\end{tabular}

with regard to access to market information, survey results of the study revealed that a considerable percent of the respondents $(76.7 \%$ and $64.4 \%)$ replied as they are not using magazines and mass Medias as a source of market information respectively. only less than a fourth $(23.3 \%)$ and $35.6 \%$ of the study participants replied as they are using magazine and mass media as a source of market information respectively. This was also confirmed by key informant interview participants. key informants of the study mentioned that the Ethiopian commodity exchange disseminates market-related information to participants through magazines, newspapers and mass media. According to the survey results about $58.9 \%$ and $52.8 \%$ of the respondents revealed that they were receiving market related information via SMS and internet database system respectively. Consistent with these findings of Shahidur et al (2010) found out that Communications and transportation infrastructure is critical to a functioning exchange. In line with this, key informants of the study also argue that presence of a reliable and functioning system for transportation and distribution, that facilitate a credible delivery system, is a prerequisite for successful commodity exchange system establishment.

Results of the study depicted below indicated that about $51 \%$ of the respondents who use SMS and internet were found not satisfied with the service. In contrary to this, $49 \%$ of the survey participants reported their satisfaction with the SMS and internet service provided by ECX to facilitate the exchange. Consistent with this finding of a study conducted by Celeste Aida Molina Fernandez (2010) revealed that internet and telecommunication services in the ECX are still poor and quite deficient (sometimes non- existent) to disseminate information to the participants.

Regarding the pricing of commodities, about $29 \%$ of the respondents reported that the actual price at the time of the exchange was similar with the information they have in the local and foreign markets. As results of this study revealed that a considerable proportion of the respondents $(71.2 \%)$ were found unsatisfied with buying and selling of commodities related to the actual price and information they have in the local and foreign market. According to information obtained from key informant interviewee, price fluctuations were mentioned as the probable reason for the aforementioned difference.

\section{Warehousing and Quality Grading}

According to the key informant interview and secondary data analysis result, Ethiopian commodity exchange has 35 privately and 16 government-owned warehouses in 16 different parts of the country. As results of the aforementioned source confirmed these warehouses are not adequate enough to accommodate all the requests of participant's commodities. In line with this, survey results of the study verify that about $69.9 \%$ of the respondents 
responded as ECX did not have adequate storage service which accommodates the request of the participant's commodities. Whereas, $30.1 \%$ of the respondents revealed that the Ethiopian commodity exchange has adequate warehouse to accommodate commodities in case of request from the participants.

Likewise, findings of this study depicted below in table 4 indicated that a relatively higher percent of the respondents $(61.6 \%)$ responded as the Ethiopian commodity exchange recording and management system of the warehouse was not as such satisfactory while $38.4 \%$ of the respondents were found satisfied with the recording and management system. As findings by Gideon E. Onumah (2010) indicated a professional skill in the warehousing is necessary if storage losses are to be kept at a minimum.

Concerning the warehouses' storage costs, about $68.5 \%$ of the respondent replied as it were fair and affordable while $31.5 \%$ of the respondents replied as it were not fair and affordable. Likewise, findings portrayed in table 5 revealed that about $23.3 \%$ of the respondents replied as the penalty cost for the delay made to withdraw the commodity on time from the warehouse was fair and affordable. In contrary to the above findings, the majority $\mathbf{( 7 2 . 6 \% )}$ of the respondents revealed that the penalty cost for the delay made to withdraw the commodity on time from the warehouses was very much higher. consistent with this, key informant interviewee was also said that the penalty cost for not withdrawal on time from the warehouses was $2 \%$ of the price of the commodity $(2 \%$ of the price of 1 quintal) and added that because they were transacting in millions of birr $2 \%$ of penalty was much higher. Table 5: warehouse and quality grading System ECX

\begin{tabular}{|c|c|c|c|c|}
\hline & Response & $\begin{array}{l}\text { No of } \\
\text { respondents }\end{array}$ & $\%$ & $\begin{array}{l}\text { t-test for Equality } \\
\text { of Means }\end{array}$ \\
\hline \multirow[t]{3}{*}{ Adequacy of warehouses } & Adequate & 22 & 30.1 & \multirow{3}{*}{.223} \\
\hline & No & 51 & 69.9 & \\
\hline & Total & 73 & 100 & \\
\hline \multirow{3}{*}{$\begin{array}{l}\text { Recording and management system of } \\
\text { the warehouse }\end{array}$} & Yes & 28 & 38.4 & \multirow{3}{*}{.597} \\
\hline & No & 45 & 61.6 & \\
\hline & Total & 73 & 100 & \\
\hline \multirow[t]{3}{*}{ Warehouse storage cost } & fair and affordable & 50 & 68.5 & \multirow{3}{*}{.540} \\
\hline & Expensive & 23 & 31.5 & \\
\hline & Total & 73 & 100.0 & \\
\hline \multirow[t]{4}{*}{ Penalty cost for the delay to withdraw } & Low & 3 & 4.1 & \multirow{4}{*}{.733} \\
\hline & Fair & 17 & 23.3 & \\
\hline & High & 53 & 72.6 & \\
\hline & Total & 73 & 100.0 & \\
\hline \multirow{3}{*}{$\begin{array}{l}\text { The time is given to store and transfer } \\
\text { commodities }\end{array}$} & Enough & 34 & 46.6 & \multirow{3}{*}{$.095 *$} \\
\hline & No & 39 & 53.4 & \\
\hline & Total & 73 & 100.0 & \\
\hline \multirow[t]{3}{*}{ Warehouse security } & Secured & 50 & 68.5 & \multirow{3}{*}{.907} \\
\hline & No & 23 & 31.5 & \\
\hline & Total & 73 & 100.0 & \\
\hline \multirow[t]{3}{*}{ Presence of quality control specialist } & Yes & 45 & 61.6 & \\
\hline & No & 28 & 38.4 & \\
\hline & Total & 73 & 100 & .298 \\
\hline \multirow[t]{3}{*}{ Grading and sampling system } & Satisfactory & 24 & 32.9 & \multirow{3}{*}{.552} \\
\hline & No & 49 & 67.1 & \\
\hline & Total & 73 & 100.0 & \\
\hline \multirow{5}{*}{$\begin{array}{l}\text { Reasons for unsatisfactory quality } \\
\text { grading and sampling system }\end{array}$} & Bias & 27 & 37.0 & \multirow{5}{*}{.651} \\
\hline & lack of knowledge & 25 & 34.2 & \\
\hline & Corruption & 15 & 20.5 & \\
\hline & $\begin{array}{l}\text { Lack of measuring } \\
\text { equipment }\end{array}$ & 6 & 8.2 & \\
\hline & Total & 73 & 100.0 & \\
\hline
\end{tabular}

Table 5, above indicated that $46.6 \%$ of the study participants replied the time given to store and transfer commodities were adequate enough. In contrary to the aforementioned result, $53.4 \%$ of the respondents revealed that the time given to store and transfer the commodities are not adequate enough. This, according to key informant interviewee, is highly associated with the absence of the warehouse in the vicinity. According to the information obtained from this source, the Ethiopian commodity exchange warehouses were found out of Addis Ababa and the 
infrastructure development/transportation was not much developed.

As depicted in the above table 5 of the study, a relatively higher percent of the respondents $(68.5 \%)$ believed the security of the warehouse in case of risky casualties like theft and fire. According to the key informant interview, the exchanges were insured by the insurance companies if anything happens to the stored commodities. According to this source the exchange will take the risk for stored commodities, not the participants. But $31.5 \%$ of the respondents were found not confident enough in the warehouse for risky causalities like theft and fire. According to Gideon E. Onumah (2010) finding shows network of secure, well-run warehouses which are accessible to various depositors is essential prerequisite for a successful accomplishment of commodity exchange. The research result of the paper concurs' with above researchers result.

As the finding of the research found the relatively higher percentage of the respondents $(61.6 \%)$ revealed the Ethiopian commodity exchange warehouses were equipped with quality control specialist. In line with this, the key informant interview also confirmed that the ECX warehouses have well-equipped grading laboratories and quality control, specialist. On the other hand a considerable percent of the respondents (38.4\%) replied as the exchange lacks well-equipped quality control specialists although they are a prerequisite for successful commodity exchange.

Even if the ECX has grading laboratories and quality control specialist, about $67.1 \%$ of the respondents as depicted above indicated that the members were not satisfied with the grading and sampling of commodities conducted in the warehouses. As results of the study portrayed in the above table indicated $45.2 \%$ of the respondents responded as the grading and sampling specialists of the ECX warehouses were made bias while quality grading and taking samples of the commodities. Consistent with this, $27.3 \%$ of the respondents showed that the exchange was prone to corruption. And the other $26 \%$ verified there was a lack of knowledge in sampling and grading. In contrary to this, key informant interview indicated that the exchange was free from bias and corruption and added that the quality and sampling system of the exchange is done through coding; the specialist did not know whose commodity is while giving quality grading and taking sample of the commodities of the participants. In addition, the interviewee verified that the main problem of the Ethiopian commodity exchange participants was lack of awareness in quality grading and sampling system of the exchange.

A research conducted by Dawit Alemu and Gerdien Meijerink (2010) showed that exporters in Ethiopia face several quality problems in terms of quality grading, sampling representation of commodities and adulteration especially by mixing sesame seed of different origin. As per the finding, this has led to difficulty in setting prices for certain quality grades. Quality grading of the Ethiopian Quality and Standard Authority (EQSA) takes a long time as well as prone to corruption. Moreover the results of the research match with the above scholar's result.

A t-test analysis for equality of means between full and limited participant of ECX for the aforementioned warehouse and quality grading variables revealed that adequacy of warehouses, recording and management system, storage cost, Penalty cost for the delay to withdraw, security, Presence of quality control specialist, grading and sampling system and reasons for unsatisfactory quality grading were not found as such significant. Unlike the aforementioned variables, the two variables under consideration, full and limited participant, have shown a significant difference with regard to the time given to store and transfer commodities,

\section{Liquidity}

As a result of the study verified in Table 6 , about $82.2 \%$ of the respondents replied that credit was not easily available and the requirements to take credit were difficult to apply and time-consuming to the participants. Whereas $17.8 \%$ of the respondents replied that credits were easily available if needed by the participants. Inconsistent with this majority of the respondents confirmed source credit were banks and the interest rate that the participants paid for the aforementioned financial institution was fair and affordable.

The result of the study revealed $74 \%$ of the respondents replied that the Ethiopian commodity exchange did not provide fully articulated and managed warehouse receipt system or in-store credit for the participants. Besides, key informant's interview verified that the exchange did not fully y to apply WRS. Only United bank of Ethiopia was started to provide in-store credit for the member participants and this was not enough. In contrary to this $(26 \%)$ of the respondents verified the exchange was provided in-store credits. Furthermore, according to Gideon E. Onumah (2010) "Liquidity in the agricultural trade can be enhanced if lenders aversion to the provision of inventory finance is addressed through the development of credible warehouse system which allows stored commodities to be used as collateral for loan". And the finding of the research was found coinciding with Onumahs' result. 
Table 6: Liquidity Characteristics of ECX

\begin{tabular}{|c|c|c|c|}
\hline & & No of respondents & Percent \\
\hline \multirow[t]{3}{*}{ Credit availability } & Easily available & 13 & 17.8 \\
\hline & Not available & 60 & 82.2 \\
\hline & Total & 73 & 100.0 \\
\hline \multirow[t]{3}{*}{ Availability of in-store credit } & Yes & 19 & 26 \\
\hline & No & 54 & 74 \\
\hline & Total & 73 & 100.0 \\
\hline \multicolumn{2}{|c|}{ Matching up of each buy and sell Yes } & 66 & 90.4 \\
\hline \multirow[t]{2}{*}{ transaction } & No & 7 & 9.6 \\
\hline & Total & 73 & 100.0 \\
\hline \multicolumn{2}{|c|}{ Ability to manage funds flows in Yes } & 58 & 79.5 \\
\hline \multirow[t]{2}{*}{ volatile days } & No & 15 & 20.5 \\
\hline & Total & 73 & 100.0 \\
\hline \multirow{3}{*}{$\begin{array}{l}\text { Coordination } \\
\text { members }\end{array}$} & Yes & 61 & 83.6 \\
\hline & No & 12 & 16.4 \\
\hline & Total & 73 & 100.0 \\
\hline \multirow{3}{*}{$\begin{array}{l}\text { Availability of Adequately equipped } \\
\text { ECX clearing and settlement system }\end{array}$} & Yes & 60 & 82.2 \\
\hline & No & 13 & 17.8 \\
\hline & Total & 73 & 100.0 \\
\hline
\end{tabular}

As the above table 6 , shows more than $90.4 \%$ of the respondents revealed the Ethiopian commodity exchange clearing and settlement system was well equipped in providing effective and efficient services for the participants in assuring payment to the seller, matching up each buys and sells transaction, and integrating the market place of the exchange. In line with this, key informant interview verified that ECX is well equipped and adequate enough to provide the clearing and settlement service.

In connection with the above findings $79.5 \%$ show that the ECX banking settlement provided responsible service for the members in order to manage their fund flows in volatile days and $83.6 \%$ of the respondents revealed that the banking system of the exchange was good in coordinating members and the exchange for the effective transaction and in providing service for the participants to manage their working capital. In addition to this the results portrayed in the above table 6 , indicated that about $82.2 \%$ of the respondents were satisfied with the infrastructure, technology and trained manpower of the ECX banking settlement. Consistent with this, key informant interview also confirmed as the ECX was working with seven banks which provided liquidity (banking settlements) and day to day transaction service for the members.

\section{Regulation}

As results of the regulation related analysis of the study depicted in table 7 , verified about $78.57 \%$ of the respondents confirmed the sole control of dishonest and irresponsible practice in the exchange process by the ECX authority. In contrary to the aforementioned result, $21.43 \%$ of the respondents replied that the authority did not control the irresponsible and dishonest act of the exchange. In addition, according to the results of the study $75.71 \%$ of the respondents verified that dishonest or irresponsible practice by counterparties, intermediaries or banks effectively controlled by the exchange authority and the remaining percentage $(24.29 \%)$ were not satisfied with the controlling of dishonest and irresponsible practice by the counterparties, intermediaries or banks. This also confirmed by key informant interview. According to information obtained from key informant interview, all the illegal acts of the participants and the exchange are controlled or supervised by the ECX authority.

As results of the analysis revealed $81.69 \%$ of the respondents were confident enough in the Ethiopian commodity exchange in enforcing contracts that were made among the participants while only $18.31 \%$ were portrayed the ECX did not enforce contracts that were made by the participants in the exchange. In contrary to findings of this study, findings of Shahidur et al (2010) verifies that the real challenge in African commodity exchange is not the development of grades but the enforcement of contracts that use those goods.

Concerning the arbitration mechanism of ECX, about $70.42 \%$ of the respondents were satisfied with the Arbitration mechanism for dispute settlement of the Ethiopian commodity exchange. In the other side, 29.58\% of the study result was verified that the Ethiopian commodity exchange did not provide an arbitration mechanism for dispute settlements. 
Table 7: Regulation of ECX

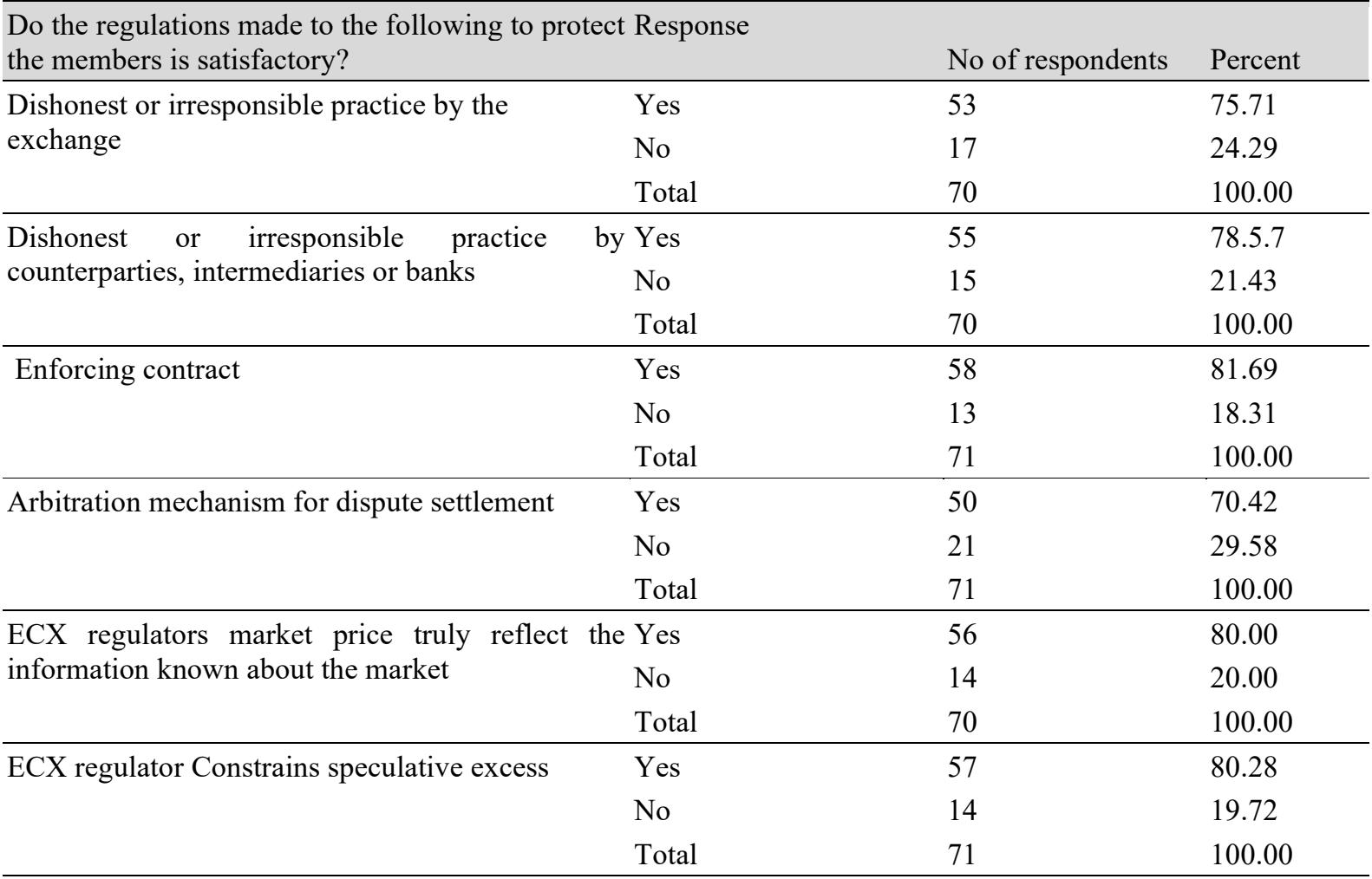

As table 7 , above verified $80 \%$ of respondents said that the ECX was committed to regulating the market to truly reflect the market price information known about the market. And $20 \%$ of the study respondents revealed that the ECX did not regulate the market to truly reflect the market price information known about the market. As in table 7, depicted majority (80.28\%) of the respondents portrayed that the ECX authority regulates the speculative excess of the member participants. In contrary to this, $19.72 \%$ the respondents replied that the ECX authority did not control the speculative excess of the member participants. The key informant interview verified that the regulator was used 5\% up and down price ceiling in order to control the exchange market.

\section{Determinants of membership participation category \\ Results of the Binomial Logit Model}

Analysis carried out on the membership category revealed that a significant proportion of ECX participants were found to be participating in a category in which they are not interested. Hence the need to exert extra efforts so as to make them participate in their interest is incontestable. But any effort intended to achieve the aforementioned objective needs to sort out the relative strength of the expected influencing variables. To this end, binary logistic regression was used to pinpoint the variables that really matter and hence, needs to be considered in the future intervention. As portrayed in, table, Hosmer and Lemeshow test statistics of this research were found to be significant (with value of greater than 0.05 ), ascertaining that the model is pretty fit in terms of predicting and describing the data adequately. Consistent with the goodness of fit, the classification table confirms that binary logistic regression model managed to predict about 89 percent of the response correctly.

A range of socio-economic and institutional variables is found to have an influence on ECX participant's decision to participate in different categories. The relative strength and direction of the effect of the variables on the status of participants through their estimated coefficient are described as follows. 
Table 8; Binary Logistic Regression Result for Determinants of membership category

\begin{tabular}{|c|c|c|c|c|c|c|}
\hline \multicolumn{7}{|c|}{ Dependent Variable: membership status } \\
\hline Ser. No. & Variables in the Equation & $B$ & S.E. & Wald & Sig. Level & $\operatorname{Exp}(B)$ \\
\hline 1 & education & -.402 & .356 & 1.277 & .258 & .669 \\
\hline 2 & occupation & -1.991 & 1.109 & 3.223 & $.073 *$ & .137 \\
\hline 3 & Time of participation & -1.679 & .470 & 12.748 & $.000 * * *$ & .186 \\
\hline 4 & Credit availability & -1.261 & .876 & 2.073 & .150 & .283 \\
\hline 5 & best membership category & -.318 & .674 & .222 & .637 & .728 \\
\hline 6 & Limited membership seat & -2.492 & .878 & 8.057 & $.005 * * *$ & .083 \\
\hline 7 & Membership requirement & -.476 & .825 & .333 & .564 & .621 \\
\hline 8 & Membership seat fee & -1.606 & .836 & 3.691 & $.055 *$ & .201 \\
\hline & Constant & & 2.923 & & .000 & \\
\hline
\end{tabular}

Enormous literature and findings verified as the education status of commodity exchange participant are a key variable in the overall participation. In light of this, it was hypothesized that those participants who have secured tertiary level of education have better chance of being full participant than they otherwise might be. Contrary to the expectation, results of the binary logistic regression model analysis revealed as it is not a significant variable even at the higher-level significance. However, the relationship between the two variables was found to be positive as hypothesized. This suggests that the probability of educated ECX participants to be full member participant were found to be higher as compared to those who have low level of education.

Concerning the occupational status of participants, it was hypothesized that those participants who committed their time and resource for the business activity (full-timer merchants) have a better chance of being full members than those of par timers. As, the coefficient for the variable, occupational status of the participant was found significant at $10 \%$ level of significance. It indicates that as the participants devote their time and resource in the exchange, they have higher chance to become a full member than those of the participants who consider participating in the exchange as part-timers.

Similarly, the coefficient for the time of participation was found to be a statistically significant determinant of member participant in the exchange at level of significance of $1 \%$, which shows as the participants started to participate in the exchange earlier by one year, they have a higher chance of being a full member than the others. It was expected that members who started to participate in the ECX earlier have better chance of becoming a full member participant than otherwise might be.

It was hypothesized that the higher the credit availability the higher will be the participants entering into full membership participation. This was due to the chance that credit availability increases the financial strength of participants because membership is acquired through bid agreements. Likewise, the result of the model verified that credit availability was found to be an anon significant variable. However, the relationship between the two variables was found to be positive as hypothesized. This indicates that the probability of getting a higher credit by the participants has was found to have a chance to be full membership as compared to those who have low-level access to credit.

The other determinant variable in the logistic regression analysis was limited membership seat. And it was expected that the higher the full membership seat the then participant's chance of participating in the full membership category will be higher than in limited membership. In line with this, the result of the regression model revealed that the variable was positive and highly significant at $1 \%$ which indicates limited membership seat has its own impact on member participates to participate into the full membership participation. In another way the higher the membership seats the better the participants will participate in full membership categories than the other.

On the other hand, the other variable which determines the membership category was the membership requirement. And it was hypothesized that the membership criteria are expected to have an impact on the participant's membership category choice. As the results of the regression analysis revealed that membership requirement was found to be insignificant to the choice of membership categories: means that membership requirement criteria were not as such pre-request to participate into the full membership category. However, the relationship between the two variables was found to be positive as hypothesized. This suggests that the probability of membership requirement criteria of ECX have positive relationship to be full member participant.

It was known that the ECX membership seat was sold to the participants through bid agreements. Even though it was a bid, the participants were complaining about the membership seat fee as higher. And the expectation of the study was the higher membership seat fee the lower the participation into the full membership categories. Inconsistent with this the logistic regression model result verified that the variable had positive and high level significant at $1 \%$. This indicates that membership seat fee is a highly determinant factor to participate into the full membership category. The higher the membership seat fee the lower the participation of members into full member 
category or the higher the fee the higher the participants will shift to participate into limited membership category.

\section{Conclusion}

The Ethiopian Commodity Exchange was established to revolutionize Ethiopian agriculture and transform the economy through a dynamic, efficient and transparent marketing system. Properly implemented and regulated, commodity exchanges can contribute greatly to the achievement of a country's economic and developmental goals and strengthen the bargaining power of farmers and other participants.

Practically the exchange is employing an open outcry trading system and spot contracts. To this end, ECX and the authority were found playing an important role in enforcing of contracts, in controlling dishonest or irresponsible practice by counterparties, intermediaries, banks constraining speculative excess and arbitration mechanisms for dispute settlements.

In addition to the above as the finding of the study found the bank clearing and settlement of the exchange was adequately equipped with technology, infrastructure and manpower in matching up of each buy and sell transaction, coordination of members and the exchange.

As a perusal of the overall analysis revealed that higher transaction cost, price fluctuation, poor ICT infrastructure, lack of adequate warehouses that accommodate ECX participants request, poor recording and management system of the warehouses; higher penalty cost imposed for the participants for not withdrawing their commodity from the warehouses, inefficient and inadequate in-store credit; expensive membership seat fee, transparent quality grading and sampling system, were found to be amongst the forefront bottlenecks/constraints to the development and success of ECX.

According to the results of binary logistic regression model occupation, time of participation, limited membership seat and membership seat fee were found to be highly significant variables and were found to be the most determinant factors that hinder ECX participants to participate into the full membership category or membership participation that they want to participate.

\section{Recommendation}

Even if ECX is not evolved into mature and competent commodity exchange, results of the finding revealed that it was gaining a positive momentum towards achieving its intended goal. In light of this and other important findings of the study, the following priority areas are forwarded for consideration for future intervention

- $\quad$ ECX needs to consider and overlook the membership criteria should increase its full membership seat in order to accommodate a higher number of participants who were participating in the limited membership.

- Membership seat fee paid by the member participants was very high and if this continued the purpose of its establishment will be in question. With the current trend, the exchange membership will be dominated by richer families excluding farmers and other middle-income participants. So ECX authority and the exchange should evaluate the financial membership criteria and should adjust it to include all the participants from all parts of the region without income discrimination.

- The ECX currently use spot contracts due to these members of the ECX were faced a price fluctuation in buying and selling of commodities. So as to minimize the aforementioned problem, ECX should try to apply future contracts/derivative in addition to that of spot contract to reduce price risk. Futures contract market in commodity exchange is largely used as risk management or hedging mechanism.

- The exchange system was carried out using open outcry trading however it should use electronic trading in addition to the open outcry. Since electronic trading system reduced price movement, it would lead to lower volatility, lower risk in the market and higher liquidity by increasing the speed of transactions and lowering transaction costs, limiting informational asymmetries between trading interests, and increasing access to markets regardless of one's geographical location.

- The warehouse credit system (in-store credit) of the exchange was inefficient and practically nonexistent. For the higher liquidity of the exchange it should apply in-store credit by all licensed banks of the exchange and should give a higher concern and commitment in effectively and efficiently using of WRS.

\section{References}

Alemu, D., \& Meijerink, G. (2010). The Ethiopian commodity exchange: An overview. Ethiopian PUlses, Oilseeds and Spices Processors Exporters Association and Wageningen University.

Bose, S. (2007). Commodity futures market in India: A study of trends in the notional multi-commodity indices. Money \& Finance, ICRA Bulletin, 3(3).

ECX (2008).Directive of the Ethiopia Commodity Exchange Authority, $2^{\text {nd }}$ Edition. Addis Ababa, Ethiopia

Gabre-Madhin, E., \& Goggin, I. (2005). Does Ethiopia need a commodity exchange? An integrated approach to market development. Addis Ababa: Ethiopian Development Research Institute, Working Paper Series, 4.

Seifu, G. (2010). Revisiting company law with the advent of Ethiopia commodity exchange (ECX): An overview. Mizan Law Review, 4(1), 102-141. 
Meijerink, G. W., Alemu, D., van der Mheen-Sluijer, J., \& Wijnands, J. H. M. (2010). Institutional innovation in African markets: can commodity exchanges address sustainability issues?.

Mheen-Sluijer, J.Van.Der. (2010). Benefiting from the gold rush-Improving smallholder sesame production in Ethiopia through contract farming (No. 13). Wageningen UR.

Norusis Marija, J. S. (1994). Advanced Statistics 6.1. USA: SPSS Inc.

Thomas, R. (2008). The Impact of Electronic Trading on the Basis at Winnipeg Commodity Exchange (Doctoral dissertation, University of Minnesota). 